\title{
Rare Observed Anatomical Variations of the Hepatobiliary System: Double Cystic Duct and Double Cystic Artery
}

\author{
Hüseyin Eken', Sercan Büyükakıncak², Hamza Çınar³, Koray Topgül ${ }^{4}$ \\ ${ }^{1}$ Clinic of General Surgery, Erzincan Mengücek Gazi Training and Research Hospital, Erzincan, Turkey \\ ${ }^{2}$ Clinic of General Surgery, Akçaabat Haçkalı Baba State Hsopital, Trabzon, Turkey \\ ${ }^{3}$ Department of General Surgery, Ordu University Faculty of Medicine, Ordu, Turkey \\ ${ }^{4}$ Department of General Surgery, Kemerburgaz University Faculty of Medicine, İstanbul, Turkey
}

\begin{abstract}
The anatomy and the potential variations of bile ducts are required to be known to prevent possible complications before laparoscopic hepatobiliary surgical interventions. There are many congenital variations at intrahepatic and extrahepatic bile ducts. Together with the increase in experience, the rate of complications have been declined to $0.5 \%$ from the first laparoscopic cholecystectomies. In this case study, we found out anatomical variations during the laparoscopic surgery of a case with bile stone-induced chronic cholecystitis and shortly reviewed the literature about the anatomical variations of bile ducts. (JAREM 2015; 5: 80-2)
\end{abstract}

Keywords: Laparoscopic cholecystectomies, Anatomical variations, double cystic duct

\section{INTRODUCTION}

Anatomical variations are important because they reduce mortality and morbidity that can occur with laparoscopy in general surgery. The anomalies of the bile ducts are quite frequently encountered; however, these are isolated artery anomalies or isolated bile duct anomalies. In this case report, we aimed to emphasize that both cystic artery and cystic duct variations can coexist.

\section{CASE PRESENTATION}

A 50-year-old female patient was admitted to our clinic with a complaint of abdominal pain in February 2013. No feature was detected in the history of the patient, who stated that her complaints had recurred from time to time for approximately 10 years. Her physical examination revealed no finding, except tenderness in the right upper quadrant with deep palpation. Abdominal ultrasonography revealed that the wall thickness of the gall bladder and bile ducts were within normal reference values, and several stones, the biggest of which was approximately $1.5 \mathrm{~cm}$ in size, were observed in the lumen. Laboratory findings were found to be normal. After establishing the diagnosis of bile stone-induced chronic cholecystitis, she was hospitalized in the clinic for surgery. She was preoperatively evaluated by the Department of Anesthesiology, and the risk was identified as American Society of Anesthesiologists (ASA) II. The patient was then operated under appropriate conditions. Laparoscopic cholecystectomy was performed. Two cystic ducts were isolated in the operation and applied dissection. When dissection was continued upwards, double cystic artery was revealed, and it was observed that they did not originate from the right hepatic artery but originated from the gastroduodenal artery and were divided into two branches at the level of the cystic ducts. Cystic arteries were also isolated and turned with a dissector. Then, one clip was put on the patient's side and one on the bladder side and cut with a scissors (Figure 1, 2). Cholecystectomy was completed after the bladder was dissected from its bed (Figure 3).

On the postoperative day 1 , the diet of the patient was planned. The patient, who tolerated the regime, was discharged from the clinic with complete recovery on the postoperative day 2 because her clinical and laboratory findings were good. Written informed consent form and verbal consent were obtained from the patient.

\section{DISCUSSION}

It is important to understand the potential anatomical variations of bile ducts for preventing possible complications before laparoscopic hepatobiliary surgical interventions (1). In the biliary system, there are many developmental variations at the intra- and extrahepatic levels (1). At present, the rates of complications have been declined to approximately $0.5 \%$ with increased number of laparoscopic cholecystectomy procedures and experience (2). The main bile duct can be explored better with an open cholecystectomy compared with a laparoscopic cholecystectomy. Accordingly, anatomical variations in bile ducts can be detected without any difficulty and danger. It is reported that the possibility of the bile duct injury is approximately 2 times higher in laparoscopic surgery than in open cholecystectomy (0.2-0.3) (3). Of these complications, $49 \%$ are intraoperatively recognized and resolved with laparoscopic interventions.

Anatomical variations are major risk factors for bile duct injuries. A great amount of these variations (24\%-37\%) are anomalies in the branching of bile ducts. Most of these anatomical variations are included within the "Calot's triangle". Therefore, the dissection of this region must be carefully performed. In patients having undergone laparoscopic cholecystectomy, the duration of hospitalization is generally 1-2 days. Biliary leakage should be 


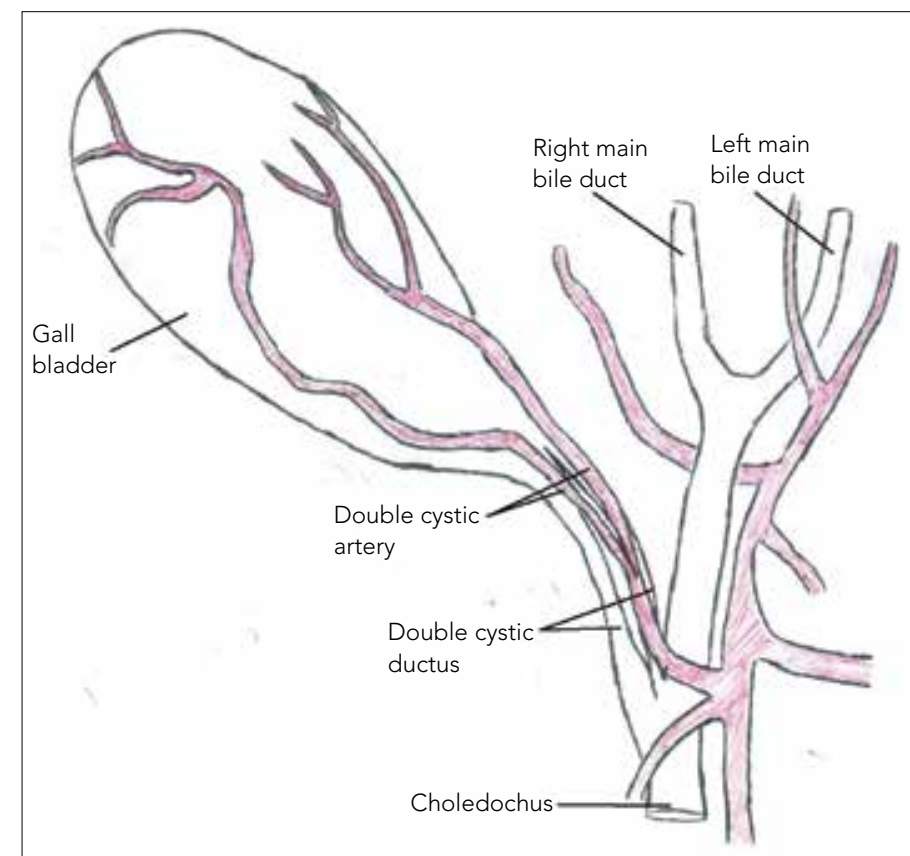

Figure 1. Representative picture of the double cystic ductus and double cystic artery

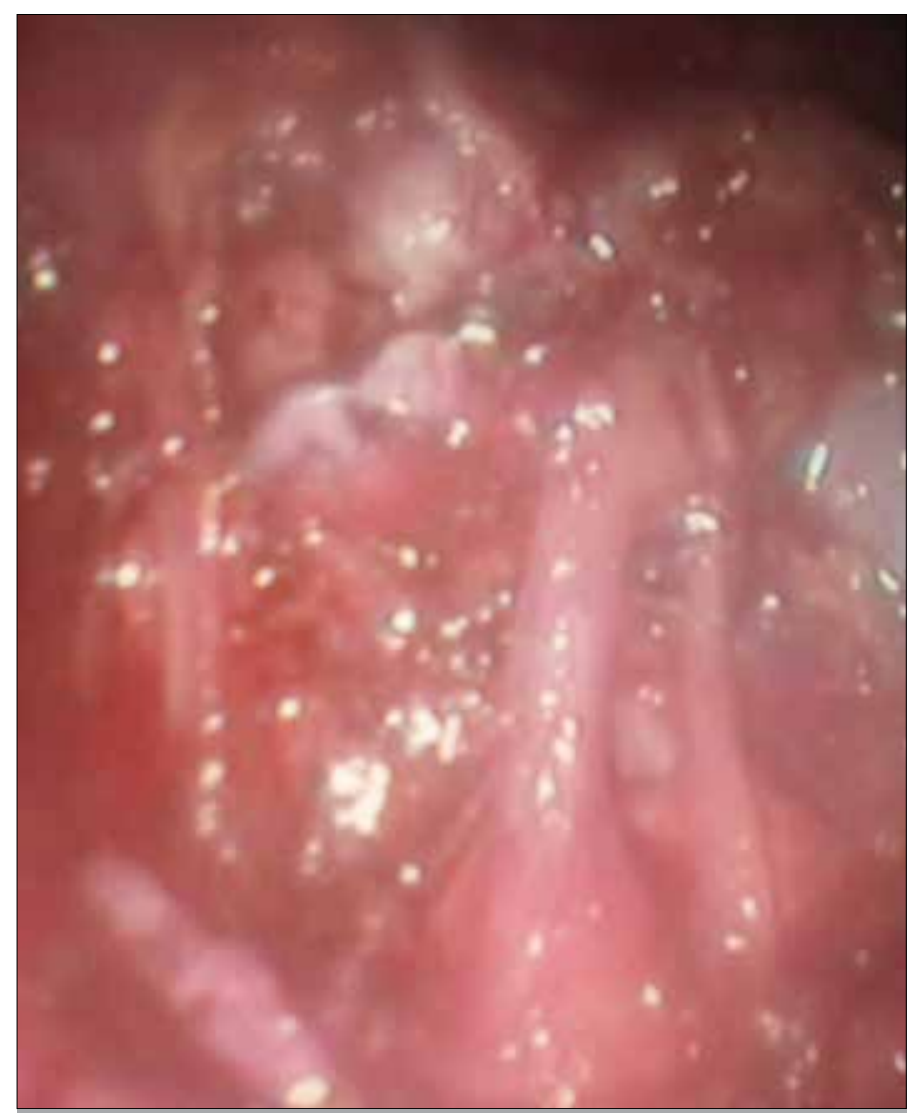

Figure 2. Intraoperative view of the double cystic ductus and double cystic artery

considered when severe abdominal pain with nausea, vomiting, fever, and abdominal distention during postoperative follow-ups occur. The characteristics of the fluid coming from the drain are

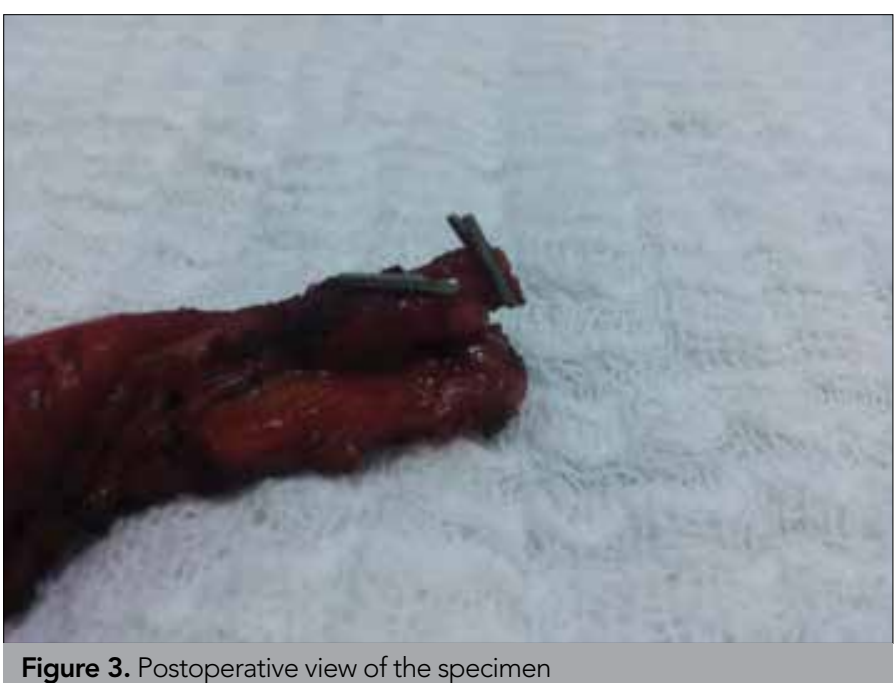

Figure 3. Postoperative view of the specimen

also important. In some situations, the drain can be congested and surgery can mislead. Impairment in the general medical condition, which is associated with peritonitis caused by the bull, can be observed. Obstructions can occur in improper manipulations with respect to inaccurate clipping or too many clips. In these situations, an increase can be observed in liver function tests and bilirubin values on day 2 or $3(4,5)$.

The variations in the intrahepatic biliary tracts were mainly divided into seven types (6). Type 1 is typical normal anatomy, which results from that the right posterior segmental ductus (RPSD) arises from the posterior of the right anterior segmental ductus (RASD) and joins the right hepatic ductus (RHD) from the medial of the right anterior ductus and then, the right and left hepatic ductus (LHD) form the common hepatic ductus (CHD). Type 2 is defined by the simultaneous emptying of RASD, RPSD, and LHD into the common hepatic ductus. Type 3 is defined as the drainage of RPSD into LHD (Type 3A), CHD (Type 3B), and cystic duct (Type 3C). In Type 4, RHD drains into the cystic duct. The presence of accessory ductus is defined as Type 5. Type 6 refers to the drainage of the segments 2 and 3 into RHD or CHD individually. And finally, complex variations that are not included in the classifications above are defined as Type 7 .

The presence of accessory ductus is a rarely observed variation, and intraoperative cholangiography is a preferred technique for demonstrating biliary system variations. Although this technique provides high quality images, it is restrictive because of some reasons, such as being time consuming, requiring experience, and low success rates (71\%).

Magnetic resonance cholangiopancreatography is a useful, noninvasive examination technique for the detection of bile ducts and their variations. For biliary leakages, endoscopic retrograde cholangiopancreatography can help to determine the type of injury. Moreover, performing sphincterotomy and/or stenting can also contribute to the treatment.

Variations are also frequently observed in the vascular system. The most common one is the cystic artery variation, particularly double cystic artery and/or cystic artery curving under the cystic duct. 
Detailed examination generally cannot be performed before surgical intervention. Possible iatrogenic traumas can be avoided with the skeptical attitude of a surgeon and demonstration of anatomical variations through examinations. More attention should be paid for younger patients and for patients having a history of recurrent pancreatitis/cholangitis attacks and malignancies.

\section{CONCLUSION}

As in all laparoscopic surgeries, the experience of surgeon is an important factor in bile duct injuries and in resolving the problem. Although to gain experience without performing surgeries creates a dilemma, the risk for biliary duct injury is higher for a surgeon having a lower experience of laparoscopic cholecystectomy but lower for an experienced surgeon. If a variation is noticed during the surgery and it is considered that it is impossible to complete the operation laparoscopically, this is not a complication. On the contrary, the occurrence of possible negative outcomes is prevented in this manner. When a surgeon notices the injury during intraoperative period but does not have sufficient experience in hepatobiliary surgery, the patient must be referred to an experienced health center, and unnecessary manipulations and repairs must be avoided.

Informed Consent: Written and verbal informed consent was obtained from patient who participated in this case.
Peer-review: Externally peer-reviewed.

Author Contributions: Concept - S.B., H.E.; Design - H.E., K.T.; Supervision - H.E., S.B.; Resource - H.Ç., K.T., H.E.; Materials - S.B., H.E.; Data Collection and/or Processing - H.Ç., K.T., H.E.; Analysis and/or Interpretation - K.T.; Literature Review - H.E.; Writer - H.Ç., H.E.; Critical Review - H.E., H.Ç.

Conflict of Interest: No conflict of interest was declared by the authors.

Financial Disclosure: The authors declared that this study has received no financial support.

\section{REFERENCES}

1. Mortelé KJ, Ros PR. Anatomic variants of the biliary tree: MR cholangiographic findings and clinical applications. AJR Am J Roentgenol 2001; 177: 389-94. [CrossRef]

2. Nuzzo G, Giuliante F, Giovannini I, Ardito F, D'Acapito F, Vellone M, et al. Bile duct injury during laparoscopic cholecystectomy: results of an Italian national survey on 56591 cholecystectomies. Arch Surg 2005; 140: 986-92. [CrossRef]

3. Düşünceli $E$, Erden $A$, Erden I. Anatomic variations of the bile ducts: MRCP findings. Tani Girisim Radyol 2004; 10: 296-303.

4. Lillemoe KD. Evaluation of suspected bile duct injuries. Surg Endosc 2006; 20: 1638-43. [CrossRef]

5. Sutton D. Textbook of radiology and imaging, Volume 2, Sixth edition, 2000; 955-80.

6. Choi JW, Kim TK, Kim KW, Kim AY, Kim PN, Ha HK, et al. Anatomic variation in intrahepatic bile ducts: an analysis of intraoperative cholangiograms in 300 consecutive donors for living donor liver transplantation. Korean J Radiol 2003; 4: 85-90. [CrossRef] 